\title{
The Impact of Using the Constructive Learning Strategy on the Level of Cognitive Achievement and Learning some Motor Skills in Swimming \\ *Pro.Ass. Dr. Bassem Saed Abdel Azim
}

Introduction and research problem

Education in Egypt is now linked to the transition to the future, from passive education to positive education, from the role of educated teacher to the role of an active mediator. States play an important role in leading, financing, and controlling the educational process, and society has become a partner for it. They are the beneficiaries of their outputs and thus reflected on their components (teachers, learners, curricula, methods and methods of teaching), which thus affects that each educational institution becomes a center of radiation to discharge experiences, abilities, talents and skills acquisition.

It is time for all education workers to join forces to benefit modern Egypt with its credibility, leaving emphasis on conservation and indoctrination and traditional teaching methods that are not in line with the requirements of the times. Innovative and creative. $(20: 12,13)$

Hassan Hussein Zeitoun, Kamal Hussein Zeitoun (2003) states that the constructive learning model works to link science with culture and society and seeks to help students build their scientific concepts and knowledge through four stages derived from the three stages of the learning cycle (concept exploration- concept extraction - concept application) These four phases are advocacy, exploration, explanation, solutions and decision-making (4: 440).

It also explains that the constructive learning model aims at making the student the center of the educational process. He discusses the problem and collects the information that he thinks may contribute to solving the

"Assistant Professor, Department of Curriculum and Instruction, Faculty of Physical Education, Al-Azhar University. 
problem, then discussing the proposed solutions with his colleagues, and then studying the possibility of applying these solutions scientifically. Through his practice of scientific thinking, he is a researcher of the concerned in addition to being a knowledge builder and participant in the responsibility of learning management and evaluation, he is more active,

Researcher and prospector to discover the appropriate solutions to the problems he faces, which is the focus of this model and the focus of his attention, the role of the teacher according to philosophy Constructivist is an organizer of the learning environment and a backup source of information if necessary and a model from which the student acquires experience to observe first and then instructs them to do some tasks in front of him and under careful observation of it, then each of them set out to work alone most of the time after that provided him with the learning tools and equipment required to complete the learning tasks In collaboration with them he thus participates in the process of learning management and evaluation (16: 11-18) (47:29)

In this regard, Khairi AlMaghazi, Bedair Ajaj (2000), Zeinab Omar, and Wafaa Moufarrej (2009) indicate that the constructive learning model helps students build their scientific concepts and knowledge. This model also emphasizes the linking of science with culture and society. The ways in which science and masters specialize in learning and working, and these four stages have two aspects are science and culture and with the different field of the lesson and its subject in terms of being a science or culture, but that the course of the lesson is one with a note of overlap and great interaction between the two sides $(108,107: 5)(7: 438-441)$

At the beginning of the third millennium it was found that the reality of the students must use modern methods of learning that combine them with the psychological and social needs of students, and develop the desired behaviors, which they desperately need in their dealings within the classroom, and in society has 
been educational psychologists and curricula to the most important Modern methods in the learning process, including the cycle of learning dimensions seven stages Seven E's constructivist. (6: 9) (74:12)

Swimming is an important basis for the practice of water sports and is one of the individual games that need to master in a clear vision of the form of teaching and learning swimming, using some technological applications on the learning outcomes of swimming methods, which requires the effort of teachers and new tasks, development remains to correct the educational message according to a specific strategy For implementation, the teacher has become a designer and programmer in addition to being a teacher, as well as the learner has become a positive role in the interaction with the elements of the educational situation. (90:10)

The educational environment of the university stage requires the teachers to make double efforts due to the high age of education for students because of the characteristic of this stage of some physical, skills and psychological problems, which necessitated attention to all factors that help to improve the skill level of the student and keep abreast of modern technologies. Suitable for modern student abilities, the most efficient methods and teaching methods are the most economical of effort and time. (90:10)

To the knowledge of the researcher and through his readings and acquainted with many previous studies found that the model of the course of constructive learning dimensions did not address any of the researchers to use in learning crawl swimmers, and unanimously the results of those researches and studies on the great role played by this model in the success of the educational process and therefore This research is an attempt to identify the impact of the use of constructive learning strategy on the level of cognitive achievement and learning some motor skills in swimming

\section{Research Goal}

Identify the impact of using the constructive learning strategy on the level of 
cognitive achievement and learning motor skills in swimming.

\section{Research hypotheses}

1- There are statistically significant differences between the averages of the pre and post measurements in the level of cognitive achievement and learning of crawling swim on the abdomen and back among the students of the experimental research group.

2- There are statistically significant differences between the averages of pre and post measurements in the level of cognitive achievement and learning of crawling swim on the abdomen and back of the control group students.

3- There are statistically significant differences between the two mean measurements in the experimental and control groups in the level of cognitive achievement and learning of crawling crawls on the abdomen and back and for the benefit of the experimental research group.

Some of the terms in the search

-Constructivist Learning Style It is "one of the methods based on constructivism and consists of four successive stages are (advocacy, exploration, proposing interpretations and solutions, taking action) and each stage performs a certain function that represents a prelude to the next stage." The students lead to the required concepts or relationships through their explanations and suggestions reached in the exploration stage and in the stage of taking actions. Lire (23: 37 - 40)

\section{Research Plan and Procedures: \\ Research Methodology:}

The researcher used the experimental method because of its relevance to the nature of the current research using the experimental design of two groups, one experimental and the other controlled by following the pre and post measurement of both groups.

\section{Society and Sample Research:}

The research community represented the students of the Faculty of Physical Education, Al-Azhar University during the academic year 2018/2019, the first semester. The research community reached (46) students. The researcher selected the research sample randomly from the third year students of the Faculty of Physical Education, Al-Azhar University. The study group was divided into two equal groups, one of which is experimental (15) students. 
The research, in addition to (16) students to conduct a survey study from the research community and outside the basic research sample.

\section{Moderate Frequency \\ Distribution and Equivalence of Sample Members:}

Calculate

the equilibrium of the frequency distribution and parity between

\section{Table (1)}

Statistical Characterization of the Research Sample in Age, Height and Weight Variables Skill level for the swimmers crawling on the abdomen, back and cognitive achievement $N=46$

\begin{tabular}{|c|c|c|c|c|c|c|c|}
\hline Serial & \multicolumn{2}{|c|}{ Varaiables } & $\begin{array}{c}\text { Measure } \\
\text { unit }\end{array}$ & SMA & $\begin{array}{l}\text { standard } \\
\text { deviation }\end{array}$ & Median & $\begin{array}{c}\text { Torsion } \\
\text { coefficient }\end{array}$ \\
\hline$\overline{1}$ & \multicolumn{2}{|l|}{$\overline{\text { Age }}$} & Year & \begin{tabular}{c|}
19.20 \\
\end{tabular} & 0.98 & 19.00 & 0.612 \\
\hline$r$ & \multicolumn{2}{|l|}{ Height } & $\mathrm{Cm}$ & 168.17 & 3.15 & 168.0 & 0.001 \\
\hline$r$ & \multicolumn{2}{|l|}{ Weight } & $\mathrm{Kg}$ & 67.12 & 2.88 & 67.00 & 0.125 \\
\hline $\bar{\varepsilon}$ & \multirow{4}{*}{$\begin{array}{l}\text { Swimming } \\
\text { crawling } \\
\text { on the } \\
\text { belly }\end{array}$} & 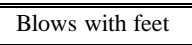 & Degree & 4.12 & $\overline{c 0.81}$ & $\bar{~} 4.10$ & 0.25 \\
\hline 0 & & Arm movements & Degree & 4.15 & 0.22 & 4.15 & 0.14 \\
\hline 7 & & $\begin{array}{l}\text { Compatibility } \\
\text { and breathing }\end{array}$ & Degree & 4.20 & 0.28 & 4.25 & 0.32 \\
\hline $\mathrm{v}$ & & Total & Degree & 12.47 & 0.64 & 12.50 & 0.36 \\
\hline$\overline{\Lambda \Lambda}$ & \multirow{4}{*}{$\begin{array}{l}\text { swimming } \\
\text { Back }\end{array}$} & Blows the feet & Degree & 4.14 & 0.22 & 4.10 & 0.145 \\
\hline 9 & & Arm movements & Degree & 4.11 & 0.15 & 4.10 & 0.32 \\
\hline 1. & & $\begin{array}{l}\text { Compatibility } \\
\text { and breathing }\end{array}$ & Degree & 4.18 & 0.13 & 4.15 & 0.25 \\
\hline 11 & & Total & Degree & 12.43 & 0.58 & 12.35 & 0.17 \\
\hline ir & \multicolumn{2}{|c|}{ Cognitive achievement } & Degree & 30.55 & 2.94 & 30.90 & 0.357 \\
\hline \multicolumn{4}{|c|}{$\begin{array}{l}\text { It is clear from Table (1) } \\
\text { that the values of torsion } \\
\text { coefficients for growth rates, } \\
\text { skill variables for swimming } \\
\text { (crawling on the abdomen - } \\
\text { back) and cognitive achievement } \\
\text { of the research sample are } \\
\text { between }( \pm 3) \text {, which indicates }\end{array}$} & \multicolumn{4}{|c|}{$\begin{array}{l}\text { the moderate distribution of } \\
\text { students in those variables. } \\
\text { Tools and means of data } \\
\text { collection: } \\
\text { A: Tools and devices } \\
\text {-Al Rustameter to measure } \\
\text { length in centimeters. } \\
\text {-Medical balance to measure } \\
\text { weight in kilograms. }\end{array}$} \\
\hline & \multicolumn{4}{|c|}{ Assiut Journal For Sport Science Arts } & & & \\
\hline
\end{tabular}

the control and experimental groups in the variables (agelength-weight), skill level and cognitive achievement of students in the crawling swimming on the abdomen and back and tables figures (1), (2) shows the moderation of the frequency distribution and parity between the two groups. 
-Swimming teaching tools (float boards - fins - paws - floats)

\section{B: Tests used in the research:} 1-Skill Performance Test:

The skill level of the third year students at the Faculty of Physical Education, Al-Azhar University was measured for the skills (swimming crawling on the abdomen - back swimming) through a committee composed of (3) faculty members of the Department of Water Sports, Faculty of Physical Education Al-Azhar University has shown their names attached (1) and each skill of swimming skills crawling on the abdomen and back was assessed

(Leg strokes, arm movements, alignment and breathing) of 6 degrees and total score for both crawl swimming, back swimming (18 degrees)

2The test of cognitive achievement of the two swimming crawls on the abdomen, back swimming) prescribed to the students of the third year of the college and the test consists of (75) words in its initial form given the correct answer one score, and the wrong answer zero (annex 4)

Final image of the test:

In light of the previous steps and procedures and the results of the exploratory experiment of the test, which resulted in determining the statistical characteristics of the test).

Executive steps of research

The program is built against a set of general objectives as follows:

-Promoting the educational process in all its aspects in general.

-Dedicated teacher to do roles such as guidance and guidance and assistance and posing problems and propose solutions

-To develop thinking, innovation, creativity, discussion, prediction, design and distance from routine and traditional methods, in line with technological advances.

-Assigning students to work collectively to develop the spirit of cooperation between colleagues.

-Emphasis on building knowledge rather than recounting it, to bring about learning kept.

What has been taken into account when setting standards for the proposed educational program- :

-General objectives of the course and sub-objectives of each unit of education. 
-The most important results that the learner is expected to achieve.

-Characteristic characteristics of learners.

-Content of educational material.

-Educational attitude and strategy of education.

\section{Third: Modified Structural}

\section{Learning Dimensions Course}

The researcher used the model of dimensions course to learn the modified structure according to "Amira Mohammed Amir (2011) (1), Hossam Eldin Nabih Abdel Fattah (2005) (3), Rasha Najih Ali (2013) (8), Sumaya Mustafa Ahmed (2001) (8) these were the following steps:

( ) Provide explanatory data. ( $\uparrow$ Present questions that lead to a sense or need for research and exploration, or an incomplete or disorganized educational material or contradictory information, has been formulated as keys to the solution leading the student to gradually discover the end result (movement.(

$(r)$ If there is more than one possible response, the teacher must be prepared with another key to guide the learner to choose only one and leave the rest to provide the additional key.

(₹)Each step builds on the response achieved in the previous step.

$\left({ }^{\circ}\right)$ In case of deviation from the discovery process, repeat the question and the key that precedes the incorrect response by a teacher.

( 7 )In the case of continuing the incorrect response, the teacher intervenes and presents another question that represents a small step helping to learn.

$(v)$ Give the student continuous feedback with the word yes or nodding the head or the word true or continue to questions that show him that he is on the right path.

$(\wedge)$ The teacher does not give the learner the answer at all.

(9)Verbal behavior can be used such as: Have you followed your answer? Do you like thinking more?

(l.)item to remind the student that when failing to discover what is required of him has the ability to search.

(1)Directives to provide the student with.

( ) I Instructions to clarify when asked to retry.

Implementation of the work using the Modified Structural 
Learning Dimension Cycle Model:

The basic phases of the modified structural learning cycle model were taken into account as follows:

*Excitation stage (activation):

At this stage, the researcher motivated the students and aroused their curiosity and interest in a certain topic through dialogue with them about the importance of these skills and the way they perform and constructive points with mentioning the legal aspects of the skill and the performance of a model and the presentation of some segments of the skill.

\section{*Exploration phase:}

At this stage, the researcher satisfies the curiosity and curiosity of the students by providing them with experiences to understand how to perform, in which the final form of the skill is discovered by displaying the skill through educational images or its performance by a student with a good level of swimming in order to try to acquire the steps Sound performance and try to draw this picture inside his mind.

\section{*Explanation stage:}

At this stage, the researcher clarified and explained the skill to be learned and tried to highlight the technical points affecting the skill in question.

\section{*Expansion Phase:}

At this stage, the researcher supervised the method of performance of the skills in question and linked the skills to each other and find the logical sequence of the skill and try to perform it properly without interference by the researcher.

\section{Extension stage:}

At this stage, the researcher supervised the students while performing the skills and clarified the relationship and the link between the skills and some of them.

\section{Exchange Stage:}

At this stage, the researcher supervised the students as they exchanged or changed ideas and experiences and gathered interesting participation through various activities.

\section{*Exam stage (Evaluation)}

At this stage, the researcher assessed the level of students' performance of the skills in question through direct observation of the performance inside the swimming pool.

\section{Premeasurement:}

The premeasurements were conducted on the two research groups for the students of the third year of the Faculty of Physical Education, Al-Azhar University on 1/3/2019, 2/3/2019 AD as follows:

-Measuring the level of skill performance of the two swimming crawls on the 
abdomen and back on 1/3/2019.

-Measurement of the level of cognitive achievement of the crawlers on the abdomen and back 2/3/2019 and includes (historical development of crawlers on the abdomen and back, the technical performance of the crawlers on the abdomen and back, the law on the two crawlers on the abdomen and back)

\section{Basic experience:}

The program was prepared using the modified construction strategy on the experimental group, in the period (4/3/19: $2 / 5 / 1929$ ) for two months by two units per week (90) minutes.
The time of the unit was distributed as follows:

Preliminary works (5) MIN

Warm-up (5) MIN

General and private physical numbers (25) MIN

The main part (modified construction strategy) (50)

MIN

The final part (5) MIN

Post measurement :

Dimensional

measurements were done as in the premeasurement from $3 / 5 / 2019,4 / 5 / 2019$ and was done in the swimming pool of the Faculty of Physical Education, Al-Azhar University

Presentation and discussion of the results:

First: View the results

\section{Table (2)}

"The significance of the differences between the pre and post measurement in the skill level of my swimming pool Crawling (abdomen-back) experimental research group $\quad \mathrm{N}=15$

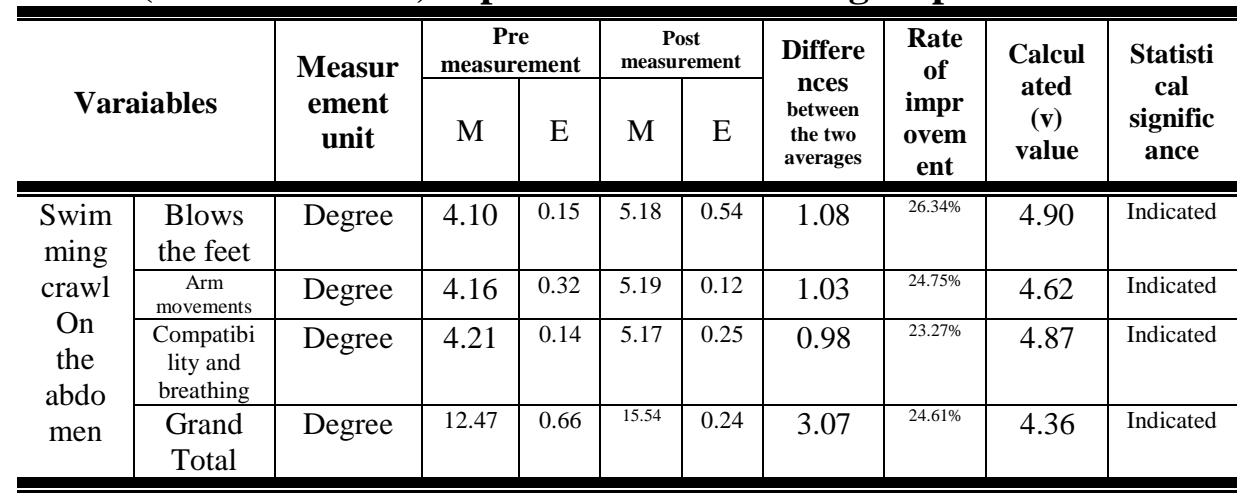


Follow Table (2)

"The significance of the differences between the pre and post measurement in the skill level of my swimming pool Crawling (abdomen-back) experimental research group $N=15$

\begin{tabular}{|c|c|c|c|c|c|c|c|c|c|c|}
\hline \multirow{2}{*}{\multicolumn{2}{|c|}{ Varaiables }} & \multirow{3}{*}{$\begin{array}{c}\text { Measur } \\
\text { ement } \\
\text { unit }\end{array}$} & \multicolumn{2}{|c|}{$\begin{array}{c}\text { Pre } \\
\text { measurement }\end{array}$} & \multicolumn{2}{|c|}{$\begin{array}{c}\text { Post } \\
\text { measurement }\end{array}$} & \multirow{2}{*}{$\begin{array}{c}\text { Differe } \\
\text { nces } \\
\text { between } \\
\text { the two } \\
\text { averages }\end{array}$} & \multirow{2}{*}{$\begin{array}{l}\text { Rate } \\
\text { of } \\
\text { impr } \\
\text { ovem } \\
\text { ent }\end{array}$} & \multirow{2}{*}{$\begin{array}{l}\text { Calcul } \\
\text { ated } \\
(\mathbf{v}) \\
\text { value }\end{array}$} & \multirow{2}{*}{$\begin{array}{l}\text { Statisti } \\
\text { cal } \\
\text { signific } \\
\text { ance }\end{array}$} \\
\hline & & & $M$ & $\mathrm{~F}$ & $M$ & $\mathrm{~F}$ & & & & \\
\hline \multirow{4}{*}{$\begin{array}{l}\text { Swim } \\
\text { ming } \\
\text { back }\end{array}$} & $\begin{array}{l}\text { Blows } \\
\text { the feet }\end{array}$ & & 4.15 & 0.21 & 5.19 & 0.14 & 1.04 & $25.06 \%$ & 4.87 & Indicated \\
\hline & $\begin{array}{l}\text { Arm } \\
\text { movements }\end{array}$ & Degree & 4.13 & 0.15 & 5.15 & 0.36 & 1.02 & $24.69 \%$ & 4.36 & Indicated \\
\hline & $\begin{array}{l}\text { Compatibi } \\
\text { lity and } \\
\text { breathing }\end{array}$ & Degree & 4.17 & 0.11 & 5.13 & 0.14 & 0.96 & $23.02 \%$ & 4.24 & Indicated \\
\hline & Total & Degree & 12.45 & 1.12 & 15.47 & 0.15 & 3.02 & $24.25 \%$ & 4.74 & Indicated \\
\hline \multicolumn{2}{|c|}{$\begin{array}{l}\text { Cognitive } \\
\text { achievement }\end{array}$} & Degree & & 28.54 & 1.19 & 42.52 & 2.18 & $\begin{array}{l}13.98 \\
\end{array}$ & $48.98 \%$ & 4.81 \\
\hline
\end{tabular}

-Tabular value $(\mathrm{T})$ at the significance level $(0.05)=1.753$

It is clear from Table (11) that there are statistically significant differences between the mean of pre and post measurements in the level of some skill variables for swimming (crawling on the

\section{Table (3)}

"The significance of the differences between the pre and post measurement in the skill level of my swimming pool

(Crawling on the abdomen-back) of the control group" $\mathrm{N}=15$

\begin{tabular}{|c|c|c|c|c|c|c|c|c|c|c|}
\hline \multirow{2}{*}{\multicolumn{2}{|c|}{ Varaiables }} & \multirow{2}{*}{$\begin{array}{l}\text { Measurement } \\
\text { unit }\end{array}$} & \multicolumn{2}{|c|}{$\begin{array}{c}\text { Pre } \\
\text { measurement }\end{array}$} & \multicolumn{2}{|c|}{$\begin{array}{c}\text { Post } \\
\text { measurement }\end{array}$} & \multirow{2}{*}{$\begin{array}{c}\text { Differences } \\
\text { between } \\
\text { the two } \\
\text { averages }\end{array}$} & \multirow{2}{*}{$\begin{array}{c}\text { Rate of } \\
\text { improvement }\end{array}$} & \multirow{2}{*}{$\begin{array}{l}\text { Calculated } \\
\text { (v) value }\end{array}$} & \multirow{2}{*}{$\begin{array}{c}\text { Statistical } \\
\text { significance }\end{array}$} \\
\hline & & & M & E & M & $\pi$ & & & & \\
\hline \multirow{4}{*}{$\begin{array}{l}\text { Swimming } \\
\text { crawl } \\
\text { On the } \\
\text { abdomen }\end{array}$} & Blows the feet & Degree & 4.11 & 0.17 & 4.90 & 0.54 & 0.79 & $19.22 \%$ & 3.99 & Indicated \\
\hline & $\begin{array}{l}\text { Arm } \\
\text { movements }\end{array}$ & Degree & 4.14 & 0.16 & 4.98 & 0.154 & 0.84 & $20.28 \%$ & 3.57 & Indicated \\
\hline & $\begin{array}{l}\text { Compatibility } \\
\text { and breathing }\end{array}$ & Degree & 4.13 & 0.12 & 4.95 & 0.32 & 0.82 & $19.54 \%$ & 3.58 & Indicated \\
\hline & Total & Degree & 12.38 & 0.91 & 14.83 & 0.25 & 2.45 & $19.78 \%$ & 3.24 & Indicated \\
\hline \multirow{4}{*}{$\begin{array}{l}\text { Swimming } \\
\text { back }\end{array}$} & Blows the feet & Degree & 4.13 & 0.17 & 4.88 & 0.54 & 0.75 & $18.15 \%$ & 3.98 & Indicated \\
\hline & $\begin{array}{l}\text { Arm } \\
\text { movements }\end{array}$ & Degree & 4.12 & 0.32 & 4.90 & 0.32 & 0.78 & $18.93 \%$ & 3.15 & Indicated \\
\hline & $\begin{array}{l}\text { Compatibility } \\
\text { and breathing }\end{array}$ & Degree & 4.15 & 0.14 & 4.98 & 0.14 & 0.83 & $20 \%$ & 3.98 & Indicated \\
\hline & Total & Degree & 12.40 & 0.64 & 14.76 & 0.15 & 2.36 & $19.03 \%$ & .3 .87 & Indicated \\
\hline \multicolumn{2}{|c|}{ Cognitive achievement } & Degree & 29.50 & 1.28 & 34.25 & 0.98 & 4.75 & $16.10 \%$ & 3.88 & indicated \\
\hline
\end{tabular}

-Tabular value $(\mathrm{T})$ at the significance level $(0.05)=1.753$

Assiut Journal For Sport Science Arts 
It is clear from Table (12) that there are statistically significant differences between the mean of pre and post measurements in the level of some skill variables for swimming (crawling on the abdomen - back) of the control group where the value of $\mathrm{T}$ calculated between (2.74 to 3.99), which is greater than its value Tabular at the significance level (0.05)

\section{Table (4)}

"Significance of differences between the two dimensions of the experimental and control groups in the skill level of swimming (crawling on the abdomen - back) $N 1=N 2=15$

\begin{tabular}{|c|c|c|c|c|c|c|c|c|}
\hline \multirow{2}{*}{\multicolumn{2}{|c|}{ Varaiables }} & \multirow{2}{*}{$\begin{array}{l}\text { Measurment } \\
\text { unit }\end{array}$} & \multicolumn{2}{|c|}{$\begin{array}{l}\text { Experimental } \\
\text { group }\end{array}$} & \multicolumn{2}{|c|}{ Control group } & \multirow{2}{*}{$\begin{array}{l}\text { Calculated } \\
\text { (v) value }\end{array}$} & \multirow{2}{*}{$\begin{array}{c}\text { Statistical } \\
\text { significance }\end{array}$} \\
\hline & & & 5 & $\varepsilon$ & s & $\varepsilon$ & & \\
\hline \multirow{4}{*}{$\begin{array}{l}\text { Swimming } \\
\text { crawl }\end{array}$} & Blows the feet & Degree & 5.18 & 0.54 & 4.90 & 0.54 & 3.80 & Indicated \\
\hline & $\begin{array}{l}\text { Arm } \\
\text { movements }\end{array}$ & Degree & 5.19 & 0.12 & 4.98 & 0.154 & 3.56 & Indicated \\
\hline & $\begin{array}{l}\text { Compatibility } \\
\text { and breathing }\end{array}$ & Degree & 5.17 & 0.25 & 4.95 & 0.32 & 3.67 & Indicated \\
\hline & Total & Degree & 15.54 & 0.24 & 14.83 & 0.25 & 3.47 & Indicated \\
\hline \multirow{4}{*}{$\begin{array}{l}\text { Swimming } \\
\text { crawl on } \\
\text { the back }\end{array}$} & Blows the feet & Degree & 5.19 & 0.14 & 4.88 & 0.54 & 3.62 & Indicated \\
\hline & $\begin{array}{l}\text { Arm } \\
\text { movements }\end{array}$ & Degree & 5.15 & 0.36 & 4.90 & 0.32 & 3.15 & Indicated \\
\hline & $\begin{array}{l}\text { Compatibility } \\
\text { and breathing }\end{array}$ & Degree & 5.13 & 0.14 & 4.98 & 0.14 & 3.84 & Indicated \\
\hline & Total & Degree & 15.47 & 0.15 & 14.76 & 0.15 & 3.15 & Indicated \\
\hline \multicolumn{2}{|c|}{ Cognitive achievement } & Degree & 42.52 & 2.18 & 34.25 & 0.98 & 3.18 & Indicated \\
\hline
\end{tabular}

- Tabular value $(\mathrm{T})$ at the significance level $(0.05)=1.697$

It is clear from Table (13) that there are statistically significant differences between the mean dimensions of the experimental and control groups in the skill performance level of the two swimming pools (crawling on the abdomen and back) where the value of $\mathrm{T}$ calculated between (3.15 to 3.84), which is greater than its value Tabular at the significance level (0.05)
Second: discuss the results

It is clear from Table (2) that there are statistically significant differences between the mean of the pre and post measurements in the skill performance level of the two swimmers (crawling on the abdomen-back) in the experimental research group where the value of $\mathrm{T}$ calculated between (4.12 to 4.90) is greater than its value The 
researcher attributed this improvement to the use of the proposed program of structural learning, which contributed to the improvement of the cognitive aspects of the experimental group, which led to an improvement in the skill level of the crawlers on the abdomen and back.

The researcher attributed this progress to the experimental group in the skill performance level of the crawling swimming on the abdomen and the back due to the learning cycle model, which consists of seven stages to move to a stage only after passing the previous stage, where students are aroused to learn and satisfy the curiosity through exploration and then Explain and clarify what they have discovered, apply it in the swimming pool and link it to the previously learned skills and then exchange ideas and experiences under the supervision of the researcher who evaluates the process to help students learn on their own and reach the best performance. The learning process develops the ability of learners to learn better. (24:15)
The researcher attributed this progress to the experimental group that used the educational program using the constructive learning model, as it encouraged students to think well and develop self-guidance in the attempts to learn skills. It also stimulates the student's thinking and works to stimulate it and make it positive. The steps taken in this way allow students to think and interpret situations, extract information and knowledge,

And then apply what has been learned, which drives students to curiosity and increase the level of ambition to learn to learn. Students are motivated to curiosity and increase their level of ambition to learn more, and increase their attention to the lesson, consistent with the results of the studies of "Ali Abdul Majeed" (2000) (13), Omar Abdullah (2004) (14) to prove the positive progress of groups The seven-stage learning cycle used knowledge literacy and information gathering among the samples under their research.

In this regard, Gaber Abdul Hamid (2006) points out 
that the model of the structural dimensions of learning stages provides an opportunity for learners to think and search for information and knowledge, which helps them to find the optimal solution to the problems that may face them. (2: 58)

The reason for the progress of the experimental group is that the educational program using the 7-stage learning dimension cycle model was positive and effective in the level of cognitive achievement in the crawlers on the abdomen and back, and believes that the formation of knowledge and access to information was formed by students in that group (experimental) through In addition, communication between students in the cooperating group leads to increased efficiency in the search for information, which in turn is reflected in increasing achievement and not forgetting the scientific material

- Guet lead group discussions to retrieve student information among themselves, leading to a deeper understanding of the Information from the premise that active learning builds knowledge through interaction with information and with the experience of others and not through the formation of images or copies of reality as well as the learner builds her own knowledge himself.

These results are also consistent with the results of studies on the role played by some of the constructive theory strategies and models in the field of cognitive achievement of some mathematical activities, which was positive and led to the progress of learners in this field of knowledge, thus illustrating the important role of that theory in building the knowledge of the learner in sports activities. Among these studies are Sumaya Mustafa (2001) (9) and Aisha Mohammed AlFateh (2005) 11, thus validating the first hypothesis of the research, which states that there are statistically significant differences between the averages of pre and post measurements in the level of cognitive achievement. And learn some skills Basic in swimming among experimental research group students.

It is clear from Table (3) that there are statistically 
significant differences between the mean of pre and post measurements in the level of some skill variables for swimming (crawling on the abdomen-crawling on the back) and cognitive achievement in swimming in the third year students control group where the value of $(\mathrm{T})$ calculated what Between (2.74 to 3.99), which is greater than its tabular value at the level of significance (0.05) and the researcher attributed that result to the regular attendance in lectures, whether practical or theoretical material swimming.

Musa Ibrahim, Adel Hassan (2003) points out that in order for the teacher to push his students to learn, he must use different methods and different methods, which requires the teacher to be fully familiar with the different teaching methods and methods and how learning occurs by students and how methods and methods affect Used to quickly achieve the goal of the teaching and learning process. (21:22)

Steven adds (2005) that it is necessary for students to be familiar with the latest methods and modern techniques that enable them to communicate knowledge to learners and create better areas to improve the teaching and learning process, hence the importance of choosing the appropriate teaching method to achieve the desired goal, and this choice depends on the experience of the teacher and the extent Recognizing the nature, components and variables of different educational attitudes (37:29)

The researcher also attributed this progress to the control group that the regularity and continuity in practice and learning with the teacher to provide a range of exercises from easy to difficult and the practice of the student gave the learner a good opportunity to learn the skills under research, which positively affected the efficiency of skill performance

Thus, the second hypothesis of the research, which provides that there are statistically significant differences between the averages of pre and post measurements in the level of cognitive achievement and learning some basic skills in swimming among the students of the control group. 
It is clear from Table (4) that there are statistically significant differences between the mean dimensions of the experimental and control groups in the level of some variables skill of swimming (crawling on the abdomen crawling on the back) and cognitive achievement where the value of $(\mathrm{T})$ calculated between (3.15 to 3.84) This is more than the tabular value at the significance level (0.05), Which indicates that the educational program using the constructive learning dimension cycle model was more positive and effective on improving learning and progressing the performance of some swimming skills than the educational program in the traditional method (explanation and presentation) used by the control group

The researcher returns e This result has a positive impact on the contents of the educational program using the seven-stage learning cycle model, which contributed effectively to achieve the educational objectives of the different behavioral to be achieved, and the proposed educational program took into account the abilities of students and their needs and tendencies and worked to involve all their senses in the educational process and give them a positive role During learning which helped to independent of their creative abilities and creative potential.

The researcher also attributed this difference between the two groups (control and experimental) in the skill performance level of some skills in swimming because the educational program using the learning cycle helped the student to learn and master the skills (under research) as this method is characterized by dividing each skill into small parts in the light of the motor sequence In this regard, Makarem Abu Harja, Mohamed Saad Zaaloul and Hani Abdel Moneim (2001) (20) state that strategies in teaching lead to increased survival and new skills for learners. Re-entrench them in their minds, reflecting on the learning process.

The researcher believes that the reason for the experimental group in the level of skill performance in swimming than the control 
group that the use of the constructive cycle model helped to attract the attention of students towards him, making the educational process more attractive and exciting and exciting for them as a result of consulting their thinking positively in addition to it has helped them to work interdependence between them $\mathrm{He}$ heard discussion, dialogue and communication, helped them to have a desire to learn, and organized their ideas sequentially to find solutions to the questions asked in the basketball skills papers (under discussion), all reflected on the progress of performance. In this regard, Mohamed Abdel Ghani Osman (2003) (17) states that education is greatly influenced by the teaching methods used by the teacher during learning and therefore education based on experimentation and application moves faster and easier than teaching. Traditional practice.

The researcher also attributes this result to the fact that the educational program using the seven-dimensional learning cycle model helped increase the level of students' achievement of facts, knowledge and information that help to remember and understand the relevant material, and it contributed significantly to the achievement of educational goals.

This is also consistent with the study of Amira Mohammed Amir (2006) (1), Hala Kassem (2013) 25, which refers to the effectiveness of constructive learning which leads to the interaction of learners with this method and challenge themselves and discover solutions to the problems and questions before them to reach Learn the skills under their research.

Thus, the third hypothesis of the research, which provides that there are statistically significant differences between the two mean measurements of the experimental and control groups in the level of cognitive achievement and learning some basic skills in swimming and for the benefit of the experimental research group.

\section{Conclusions}

-The use of constructive learning strategy improved the learning level of swimming 
crawling on the abdomen among students of the experimental research group.

-The use of the constructive learning strategy has improved the level of learning back swimming among experimental research group students.

-The use of the constructive learning strategy has improved the level of cognitive achievement among the experimental research group students.

-The use of constructive learning improved the learning level of crawlers swim on the abdomen and back and cognitive achievement in the students of the experimental research group more than the control group and used with them explanation model.

\section{Recommendations}

-Using the constructive learning strategy because of its effective role in improving the skill level in swimming.

-Use the strategy of constructive learning on different skills and age stages in swimming.

-The need to link knowledge and information within the continuous curricula in water sports to improve the cognitive aspects and expand the knowledge of graduates in swimming.

\section{References}

$\begin{array}{lrr}\text { 1-Amira } & \text { Mohamed Amir } \\ \text { (2011): } & \text { "Strategy } & \text { of }\end{array}$ constructive learning using the hemispheric device and its impact on the skill level in volleyball", scientific research published, Journal of Science and Arts of Sports, Faculty of Physical Education, Assiut University.

\section{Y-Gaber Abdel Hamid (2006): "trends and contemporary experiences in the evaluation of student and teacher performance," Dar al- Fikr al-Arabi, Cairo.}

\section{r-Hossam El Din Nabih} Abdel Fattah (2005): "The impact of the method of constructive learning on the field of cognitive and emotional and the level of skill performance of handball" $\mathrm{PhD}$ Thesis - Faculty of Physical Education - Helwan University, Cairo.

\& -Hassan Hussein Zeitoun, Kamal Hussein Zeitoun (2003): "Education and teaching from the perspective of structural theory", the book world, Cairo.

--Khairi Maghazi, Deir Ajaj

(2000): "methods of thinking 
and learning" a comparative study, the Anglo-Egyptian Library, Cairo.

`-Zaky Ibrahim Qas, Adel Mahmoud Abdel Hafez (2000): "Methods of Teaching in Physical Education", Library and Printing Press Art, Alexandria.

7-Zeinab Ali Omar, Wafaa Mohamed Moufarrej (2009): "Practical Applications in the Methods of Teaching Physical Education" Dar al-Kitab alHadith, Cairo.

8-Rasha Nageh Aly (2013) "the impact of the use of constructive learning model on learning some motor skills of gymnastics for students of the Faculty of Physical Education "- Minia University, scientific research published, Journal of Physical Sciences, Faculty of Physical Education, Minia University.

9- Sumaya Mustafa Ahmed (2001): "Strategy of constructive learning and its impact on the education of basketball skills and some knowledge outcomes for students of the Faculty of Physical Education for Girls in Cairo," a research publication, the scientific journal of physical education and sports, the thirty-eighth, Cairo.

\section{0-Shaimaa Hassan Taha El-} Laithy (2004): "Modern Techniques and their Effect on Back Swim Learning Outcomes", Published Research, Faculty of Physical Education for Girls, Helwan University, Sports and Science Magazine, Volume 20, Issue 1, January.

\section{1- Aisha Mohammed Alfatih} (2005): "The effectiveness of the use of constructive learning on cognitive concepts and the level of performance of some attacks in the sport of fencing", unpublished doctoral dissertation, Faculty of Physical Education for Girls, Helwan University, Cairo.

\section{2- Ayesh Zeitoun El Mawla} (2007): "Structural Theory and Strategies for Teaching Science", Dar El Shorouk, Cairo, 2007.

\section{3- Ali Abdel-Meguid (2000):}

"A proposed teaching strategy based on the model of constructive learning and its impact on the motor innovation of primary pupils", published research, scientific journal Faculty of Physical Education for Boys, Helwan University, No. 33, April. 
14- Amr Abdullah Abdel Qader Hussein (2004): "the impact of structural learning in the education of basic basketball skills", unpublished doctoral dissertation, Faculty of Physical Education for Boys Helwan University.

\section{5- Kamal Abdel Hamid} Zaytoun (2002): "Teaching science to understand (a constructive vision)" the world of books Cairo.

\section{6- Magdy Aziz Ibrahim} (2002): "Effective teaching what it is - skills - management -" Anglo Egyptian Library, Cairo, 2002.

\section{7- Mohammed Abdul Ghani}

Othman (2003): - motor learning and sports training, second edition, Dar Al-Qalam, Kuwait.

\section{8- Mohamed Ali El-Sayed} (2002): "Educational Media and Educational Technology", 2nd floor, Dar Al-Fikr AlArabi, Cairo.

19- Mohamed Fathy ElKordany (2011): "Swimming, education, teaching," programs, Sports World Foundation, Alexandria.

20- Makarem Helmy Abu Harga and Mohamed Saad Zaghloul Mahmoud and Hani Said Abdel Moneim
(2001). "Problems of Physical Education Curricula School Diagnosis and Treatment", Book Center for Publishing, Cairo.

\section{1- May Talaat Tolba (2011):}

"The impact of constructive learning on motor memory and the level of performance of some basketball skills" Unpublished doctoral dissertation, Faculty of Physical Education for Girls in Cairo, Helwan University.

22- Musa Fahmi Ibrahim, Adel Ali Hassan (2003): "Exercises and Sports Shows", Dar Al Fikr Al Arabi, Cairo.

23- Nabil Hussein Fadl, Fatma Rizk Atallah (2000): "Scientific Culture and Science Education", Dar Al Fikr Al Arabi, Cairo.

24-Nour Taha Ibrahim: (2014): "The impact of the use of learning dimension cycle 7 , ES structural modification on the level of learning some motor skills on the ground movements of students in the preparatory stage", scientific research published, the scientific journal of physical education and sports sciences, Faculty of Education Sports for Boys, Helwan University. 
25- Hala Kamel Kassem (2013), "The Effect of Using the Modified Learning Dimension Cycle 7, ES Modified on the Skill Performance Level of Some Combat Attack Skills Composed by Karate Beginners", Scientific Research Published, Journal of Sports Science and Arts, Faculty of Physical Education for Boys, Helwan University. 26- Walaa Shoukry Abdel Moneim (2006): "The Effect of Using Super Media on Swimming Learning", Master Thesis, Faculty of Physical
Education for Girls in Cairo, Helwan University.

\section{Foreign References}

\section{7-Eisenkraft :(2003)}

Expanding the 5E Model ,

The science teacher", vol .70, no.6 journal for high school science educators published by the national science teachers association

28-Duffy, T. M, \&Jonassen, D. H (2004): Constructivism new implicqrions for ins instructional technology Educational technology vol . 31 No .5.

29- steven .d, : (2005) coaching gymnastics successfully Engle Wood Cliffs Prentice shall 